\title{
An Uncommon Location for Granular Cell Tumor in a 10-year-old Caucasian Female
}

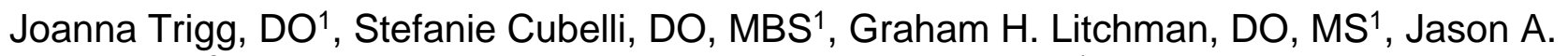
Cohen, $\mathrm{MD}^{2}$, Suzanne Sirota Rozenberg, DO, FAOCD, FAAD ${ }^{1}$

${ }^{1}$ Department of Dermatology, St. John's Episcopal Hospital, Far Rockaway, NY

${ }^{2}$ Dermpath Diagnostics, White Plains, NY

\section{ABSTRACT}

Granular cell tumors are uncommon soft-tissue neoplasms of confirmed neural origin and are typically found in females of African descent between 30 and 60 years old..$^{1-3}$ Most cases are found in the head and neck region, specifically the tongue, although there have been reports of other anatomic variants in patients outside of the typical epidemiology. We report a case of a granular cell tumor in a 10-yearold Caucasian female located on the left ventral upper arm with a biopsy confirming the histopathological diagnosis.

\section{INTRODUCTION}

Granular cell tumor is a term used to describe a group of soft tissue neoplasms with cells that are made of granular cytoplasm from the accumulation of lysosomal granules. ${ }^{1}$ Granular cell tumors are rare tumors that mostly occur in adults between 30 and 60 years old, with a 1:3 male-to-female ratio, and most often in individuals of African descent. ${ }^{1,4}$ Most cases present as a poorly defined solitary tumor and a large majority are typically found in the head and neck regions, with 30\% located on the tongue because they develop from the gastrointestinal mucosa. ${ }^{3,5}$ There have been 5,039 reported granular cell tumors, of which only 128 are pediatric cases. Given the rarity of these tumors, especially in the pediatric population, clinical diagnosis is difficult and histopathologic analysis is often necessary. Here we report a case of a granular cell tumor in a 10-yearold Caucasian female.

\section{CASE PRESENTATION}

A 10 year old Caucasian girl without prior medical conditions presented with a solitary bump on the left upper extremity present for an unknown amount of years. They denied pain, discharge from the area, or changes in growth of the lesion over time. The patient denied fever or chills. On physical exam, the left ventral extremity had a slightly pink/flesh-colored, indurated, round nodule. There was no opening to the surface of the skin (Figure 1). A $2 \mathrm{~mm}$ punch biopsy revealed a proliferation of cells with oval and round nuclei and abundant cytoplasm filled with granules (Figure 2) arranged in nested aggregations throughout the dermis, without mitotic figures or atypia noted (Figures 3) consistent with granular cell tumor.

Based on the pathology reading and the fact that it was a small, solitary lesion, the tumor was very likely benign. However, given 
extension into the peripheral margin and that some cells were found around peripheral nerves, the patient ideally would have had a wide excision of the lesion to minimize the chance of recurrence. Unfortunately, she was lost to follow up.

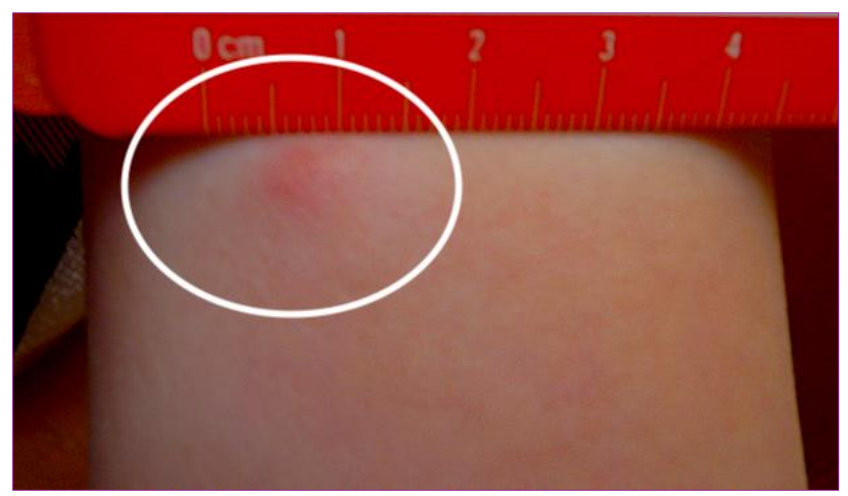

Figure 1. Granular cell tumor on proximal left arm of the patient.

\section{DISCUSSION}

Most granular cell tumors present as asymptomatic, skin-colored to brown/red, firm dermal or subcutaneous nodules. ${ }^{1,8}$ They typically range in size from $0.5-3.0 \mathrm{~cm}$. At times, the surface might be ulcerated or verrucous. ${ }^{8}$ Some lesions might also elicit pain or pruritus. They are usually slow growing benign tumors found in the oral cavity in females ages 30-50 years old of African descent. This demographic differed from that in our case of a 10-year-old Caucasian female. There are three variants of granular cell tumors. The first normal variant described above, which positively expresses the $\mathrm{S} 100$ protein. ${ }^{8,11}$ The second is a non-neural granular cell tumor which has similar features to the normal variant, but is $\mathbf{S 1 0 0}$ negative. The third is a congenital granular lesion that is typically located in the gingiva of newborns, and is also S100 negative.

Histologically, the dermis shows a nodule made of polygonal, pale-staining cells with abundant lysosomal granules which give it the name "granular cell tumor". One to three percent of cases are found to be malignant and are more likely to occur when the original tumor is found in viscera or deep soft tissue. ${ }^{4}$

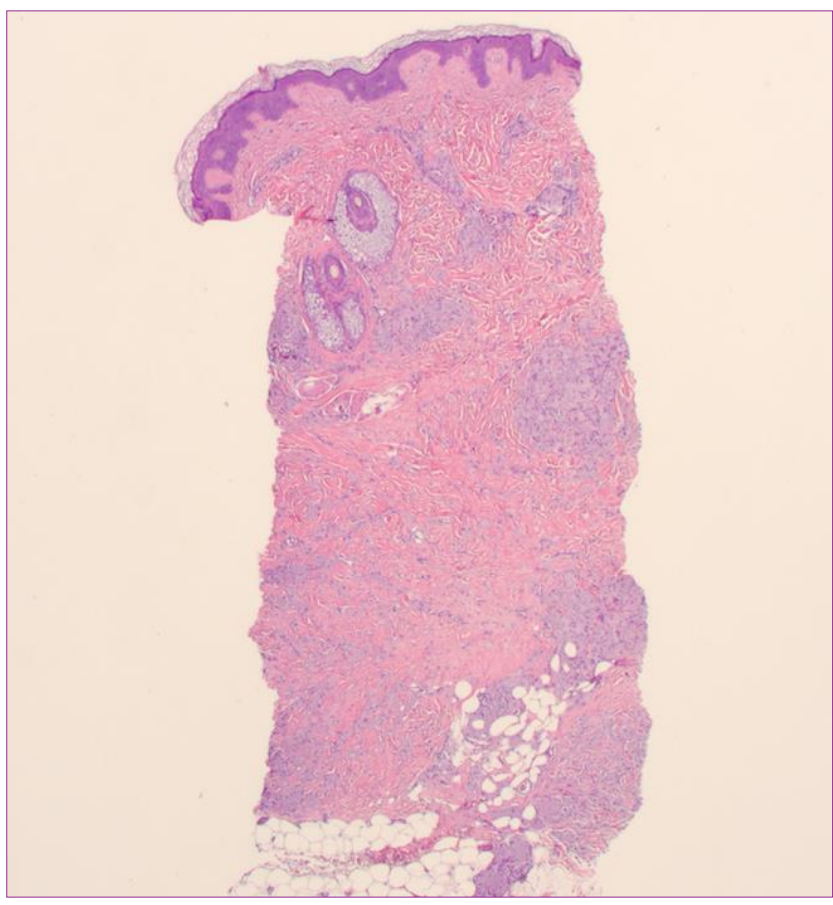

Figure 2. Granular Cell Tumor with cells that have abundant cytoplasm filled with granules and nuclei that are oval and round. No mitotic figures or atypia noted. ${ }^{7}(\mathrm{H} \& \mathrm{E}, 20 \mathrm{x})$

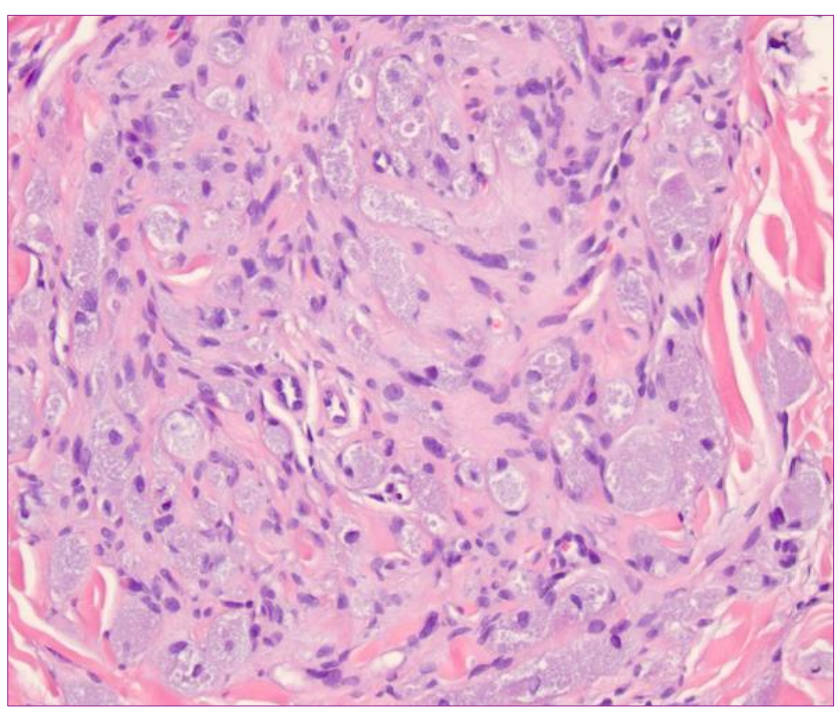

Figure 3. Cells arranged in nested aggregations throughout the dermis. ${ }^{7}$ (H\&E, 200x)

March 2021 Volume 5 Issue 2 
These malignant tumors also have a risk of metastasizing to regional lymph nodes, and, in even rarer cases, to the lungs or bone. ${ }^{9}$ Benign characteristics of granular cell tumors include: (1) origination within the skin; (2) less than $3 \mathrm{~cm}$ diameter; and (3) no new growth in long-standing lesions. ${ }^{10}$ There have been attempts to develop histopathologic criteria to identify malignant tumors. Kim and Lee report that malignancy criteria include necrosis, spindling, vesicular nuclei with large nucleoli, increased mitotic activity (more than 2 mitoses per 10 high power fields at 200 magnification), high nuclear to cytoplasmic ratio, and pleomorphism. ${ }^{10}$ If 3 or more of these criteria are present, the tumor can be termed malignant. 6,10 If one or two criteria are found, then the tumor may be considered atypical. ${ }^{6}$ If only one criterion is met, the tumor is classified as benign. In this case, our patient had both clinical and histopathologic characteristics of a benign granular cell tumor.

Clinical differential diagnosis includes dermatofibroma, regressing verruca, adnexal neoplasms, basal cell carcinomas, leiomyomas, and leiomyosarcomas and even squamous cell carcinoma if the tumor is located near an epithelial surface and demonstrates pseudoepitheliomatous hyperplasia.5,9, 10 Because a granular cell tumor is uncommon and has no specific clinical features, diagnosis can be clinically challenging.

Treatment of granular cell tumors is with complete excision. There is a higher local recurrence rate if the tumor is not excised with clear margins, likely due to plexiform or perineurial growth patterns. ${ }^{1} \mathrm{Kim}$ and Lee report that tumors on extremities could infiltrate deeper than clinically expected, and a wider, deeper margin should be considered. ${ }^{10}$ Depending on location, further surgical management may be appropriate.

\section{CONCLUSION}

Granular cell tumors are rare soft tissue neoplasms. They are most likely found in the head and neck region of females between 30 and 60 years old. However, tumors have been reported in unusual populations, specifically, in pediatric patients. Therefore, granular cell tumors should be considered in the differential diagnosis of a solitary lesion on the extremity of a pediatric patient.

\section{Conflict of Interest Disclosures: None}

Funding: None

Corresponding Author:

Steganie Cubelli DO, MBS

9 Drake Court, Boonton, NJ 07005

Phone: 201-213-1503

Email: cubelli90@gmail.com

\section{References:}

1. Argenyi ZB. Neural and Neuroendocrine Neoplasms (Other than Neurofibromatosis). In: Dermatology. Vol 115. Philadelphia, PA: Elsevier; 2016:2050-2067.

2. Daulatabad D, Grover C, Tanveer N, Bansal D. Granular cell tumor in a child: An uncommon cutaneous presentation. Indian Dermatology Online $\mathrm{J}$. 2016;7(5):390-392.

3. Yasak T, Ozkaya O, Ayberk A, Kayadibi T, Erzurumluoglu N. Report of two cases of granular cell tumor, a rare tumor in children. J Pediatr Surg Case Rep. 2016;14:1-3.

4. Patterson JW. Neural and neuroendocrine tumors. In: Weedon's Skin Pathology. Vol 37. 4th ed. Philadelphia, PA: Elsevier; 2016:1041-1067.

5. Goldblum JR. Soft Tissues. In: Rosai and Ackerman's Surgical Pathology. Vol 41. 11th ed. Philadelphia, PA: Elsevier; 2018:1810-1914.

6. Fanburg-Smith JC, Meis-Kindblom JM, Fante R, Kindblom L-G. Malignant Granular Cell Tumor of Soft Tissue: Diagnostic Criteria and Clinicopathologic Correlation. The Am J Surg Pathol. 1998;22(7):779794.

7. Cohen, J. Figures 2,3. Dermpath Diagnostics. Port Chester, NY. 2018

8. James W, Berger T, Elston D. Dermal and Subcutaneous Tumors. In: Andrews' Diseases of the 
Skin . Vol 28. 12th ed. Philadelphia, PA: Elsevier; 2016:579-624.

9. Gunduz O, Erkin G, Bilezikci B, Adanali G. Slowly Growing Nodule on the Trunk: Cutaneous Granular Cell Tumor. Dermatopathology. 2016;3:23-27.

10. Kim HJ, Lee M-G. Granular Cell Tumors on Unusual Anatomic Locations. Yonsel Medical Journal. 2015;56(6):1731-1734. doi:http://dx.doi.org/10.3349/ymj.2015.56.6.1731

11. Goldblum J, Folpe A, Weiss S. Benign Tumors of Peripheral Nerves . In: Enzinger and Weiss's Soft Tissue Tumors. 6th ed. Philadelphia , PA: Elsevier; 2014:784-854. 